\title{
INHALT VON EUSEBIUS BAND V
}

Vorwort .................. Seite

Einleitung . . . . . . . . . . . . . . . . . X XI

I. Die Handschriften . . . . . . . . . . . . . . . . . . XI

II. Die älteren Ausgaben . . . . . . . . . . . . . . . . X XIV

III. Die vorliegende Ausgabe, ihre Einrichtung und Textherstellnng mit XVI Bezug auf Anlage und Ansstattung der handschriftlichen Chronik . . . XVI

IV. Verbreitung und Benutzung der armenischen Eusebius-Chronik XXXIV

V. Die Person des Ôbersetzers oder Bearbeiters . . . . . . . XXXVI

VI. Die Zeit der Abfassung . . . . . . . . . . . . . . . XXXVI

VII. Der griechische Archetypus als Quellenvorlage des Armeniers . XXXVIII

VIII. Die syrische Version als Secundärquelle für die Textgestaltung des Armeniers . . . . . . . . . . . . . . . . . . . XLIII

Zeichen und Abkürzungen . . . . . . . . . . . . . . . LV/LVI

Text der Chronik . . . . . . . . . . . . . . . . . . . 1

Die Chronographie . . . . . . . . . . . . . . . . . . 1

Die Chaldăer (bezw. Assyrer) . . . . . . . . . . . . . . 44

Die Hebräer . . . . . . . . . . . . . . . . . . . . . 34

Die Egypter . . . . . . . . . . . . . . . . . . . . . 62

Die Griechen. . . . . . . . . . . . . . . . . . . . . 80

Die Römer. . . . . . . . . . . . . . . . . . . . . . 125

Die Series Regum nebst den Mortes Imperatorum . . . . . . . . 144

Der Kanon. . . . . . . . . . . . . . . . . . . . . . 156

Kritischer Anhang zum Kanon . . . . . . . . . . . . . 228

Zusatz-Bemerkungen zum Gesamtwerk . . . . . . . . . 239

Namen-Index . . . . . . . . . . . . . . . . . . . . . 281

Berichtigungen . . . . . . . . . . . . . . . . . 320 
